\title{
Incident Management Systems and Building Emergency Management Capacity during the 2014-2016 Ebola Epidemic - Liberia, Sierra Leone, and Guinea
}

\author{
Jennifer C. Brooks, $\mathrm{MPH}^{1}$ \\ Meredith Pinto, $\mathrm{MPH}^{1}$ \\ Adrienne Gill, $\mathrm{MPH}^{1}$ \\ Katherine E. Hills, $\mathrm{MPH}^{1}$ \\ Shivani Murthy, $\mathrm{MPH}^{1}$ \\ Michelle N. Podgornik, $\mathrm{MPH}^{1}$ \\ Luis F. Hernandez ${ }^{2}$ \\ Dale A. Rose, $\mathrm{PhD}^{1}$ \\ Frederick J. Angulo, DVM ${ }^{2}$ \\ Peter Rzeszotarski, $\mathrm{MA}^{1}$ \\ ${ }^{1}$ Division of Emergency Operations, Office of Public Health Preparedness and Response, CDC \\ ${ }^{2}$ Division of Global Health Protection, Center for Global Health, CDC
}

Corresponding author: Jennifer C. Brooks, Division of Emergency Operations, Office of Public Health Preparedness and Response, CDC. Telephone: 404-639-3186; E-mail: JCBrooks@cdc.gov.

\section{Summary}

Establishing a functional incident management system (IMS) is important in the management of public health emergencies. In response to the 2014-2016 Ebola virus disease (Ebola) epidemic in West Africa, CDC established the Emergency Management Development Team (EMDT) to coordinate technical assistance for developing emergency management capacity in Guinea, Liberia, and Sierra Leone. EMDT staff, deployed staff, and partners supported each country to develop response goals and objectives, identify gaps in response capabilities, and determine strategies for coordinating response activities. To monitor key programmatic milestones and assess changes in emergency management and response capacities over time, EMDT implemented three data collection methods in country: coordination calls, weekly written situation reports, and an emergency management dashboard tool. On the basis of the information collected, EMDT observed improvements in emergency management capacity over time in all three countries. The collaborations in each country yielded IMS structures that streamlined response and laid the foundation for long-term emergency management programs.

The activities summarized in this report would not have been possible without collaboration with many U.S and international partners (http://www.cdc.gov/vhflebolaloutbreaks/2014-west-africalpartners.html).

\section{Background}

A functional incident management system (IMS) provides a flexible and scalable approach to managing public health emergencies and includes principles such as modular organization, incident action planning, manageable span of control, resource management, integrated communication, and chain of command (1). Before the 2014-2016 Ebola virus disease (Ebola) epidemic in West Africa, limited capacity existed in Guinea, Liberia, and Sierra Leone for public health emergency management, which the epidemic strained further. CDC applied its IMS experience to help these countries establish IMS systems to respond to the Ebola outbreak and to future public health emergencies $(2,3)$.

\section{CDC's Role and Work with Partners}

In September 2014, as part of its response to the Ebola epidemic in West Africa, CDC established the Emergency Management Development Team (EMDT) within its IMS structure. This team coordinated and provided technical assistance to build emergency management capacity in Guinea, Liberia, and Sierra Leone, as well as in high-risk unaffected countries (Gambia, Guinea-Bissau, Mauritania, Togo, Benin, and Nigeria). EMDT was formed to address gaps in emergency management capacity in the affected and at-risk countries. For the most part, international partners who focused on emergency management had not arrived in country by this time, and a clear and pressing need was identified to begin organizing the response using established emergency management principles. 
EMDT was managed at CDC's headquarters in Atlanta, Georgia, by the Office of Public Health Preparedness and Response, Division of Emergency Operations, with leadership and subjectmatter expertise from the Center for Global Health, Division of Global Health Protection. CDC staff members deployed through EMDT were drawn from the ranks of emergency management specialists within the Division of Emergency Operations and technical experts from the Center for Global Health and other CDC programs and centers. Staff also were deployed from external partners, principally Public Health Agency of Canada (PHAC), which provided assistance and leadership to the team in Guinea. EMDT members, deployed staff, and others supporting the mission to build emergency management capacity also worked closely with Ebola response partners, including the World Health Organization (WHO), CDC Foundation, United Kingdom Department for International Development, Public Health England, eHealth Africa, International Organization for Migration, and Milken Institute School of Public Health at George Washington University.

EMDT members, deployed staff, and partners provided expertise in assisting country ministries of health and other government entities in building core IMS functions, such as emergency response planning, operations, and logistics. Deployed staff and partners enhanced emergency management capacity in three key domains:

1. Staff: Trained emergency management specialists and technical advisors able to work under a standardized organizational response structure, which promotes rapid integration of personnel and resources (2);

2. Systems: Standardized policies, processes, and procedures that are the codified basis for response activities and tasks; and

3. Infrastructure: A fully equipped emergency operations center (EOC) that facilitates, supports, and coordinates management and executive response decisions and activities for a public health emergency response. "Fully equipped" means, at a minimum, primary and redundant power supply, audio/visual functionality, computers, telephones, and Internet access.

\section{Contributions and Impact}

\section{Sources of Information and Data Collection}

To monitor progress toward key programmatic milestones and assess changes in emergency management and response capacities over time, EMDT collected information from three sources in each country: coordination calls, weekly written situation reports, and an emergency management dashboard tool. EMDT headquarters staff monitored activities and progress in emergency management capacity building primarily through coordination calls and weekly situation reports, which were generated and submitted by CDC staff deployed to West Africa. To supplement this information, EMDT obtained approval from incident management leadership to develop and use a new dashboard tool based on the three emergency management capacity domains (i.e., staff, systems, and infrastructure). Although a few assessment tools and checklists already existed, EMDT determined that a response-focused assessment tool, scaled to assess basic emergency management capacities, was needed. The initial intent of the dashboard tool was to facilitate a comprehensive evaluation of basic emergency management capacity-building activities and accomplishments. However, a scaled-down version of the tool was more appropriate, not for use as the main source of data for assessing capacity but rather as one of multiple sources to monitor progress in key areas simply and quickly.

The tool consists of the three domains of staff, systems, and infrastructure. Each domain comprises several elements developed by EMDT leadership to reflect the essential components necessary to execute basic emergency response operations. To reflect incremental increases in capacity, each element within each domain was rated on a 6-point qualitative ordinal scale, ranging from "domain element nonexistent" (lowest rating) to "basic requirement met" (highest rating). Because all three countries had little to no emergency management capacity before the Ebola epidemic, "basic requirement met" was the highest achievable rating for any given element (Table 1).

\section{Data Collection and Analysis}

Deployed staff participated in coordination calls and submitted situation reports and administered the dashboard tool. To administer the tool, deployed staff assigned one of six qualitative ratings to each domain element. Although situation reports were submitted weekly, the frequency of administration of the dashboard tool fluctuated between countries. In Liberia, the tool was administered an average of twice per month during September 2014-June 2015 and was used to assess the emergency management capacity of the Ministry of Health. In Sierra Leone, it was administered an average of twice per month during August 2014-June 2015 and assessed the progress of the National Ebola Response Centre (NERC). In Guinea, the tool was administered an average of nearly three times each month during September 2014-April 2015 and assessed the National Coordination Cell (known as Cellule), an entity reporting directly to the country's president. 
TABLE 1. Dashboard tool used for measuring emergency management capacity domains and elements and definitions of "basic requirement met" rating for each element during the 2014-2016 Ebola epidemic in West Africa

\begin{tabular}{|c|c|c|}
\hline Domain & Domain element & "Basic requirement met" definition (highest rating) \\
\hline \multirow[t]{11}{*}{ Staff } & Incident management & IM has authority to direct activities of all assigned response staff. \\
\hline & Response organization & Response staffing increases or decreases as required in a timely manner. \\
\hline & Operations & $\begin{array}{l}\text { Operations chief has authority to run the response in the IM's absence; additional staff are available for } \\
\text { response operations. }\end{array}$ \\
\hline & Watch desk & Trained watch staff routinely produces situation reports or spot reports. \\
\hline & Logistics & Chief is trained in IM principles and best practices; additional staff are available for response operations. \\
\hline & Finance/Administration & Chief is trained in IM principles and best practices; additional staff are available for response operations. \\
\hline & Plans & Chief is trained in IM principles and best practices; additional staff are available for response operations. \\
\hline & Technical & $\begin{array}{l}\text { At a minimum: epidemiology, laboratory, medical management, migration/population movement, and } \\
\text { community engagement/health education teams or task forces staffed adequately to meet response need. }\end{array}$ \\
\hline & Public affairs & Officer has authority to serve as spokesperson in the IM's absence (or dedicated spokesperson is appointed). \\
\hline & Liaison & Officers are routinely used to address requests for information and requests for assistance. \\
\hline & Response teams & Teams routinely report back to the EOC from the field according to established protocols. \\
\hline \multirow[t]{9}{*}{ Systems } & Meeting management & IM enforces meeting discipline. \\
\hline & Incident action plans & $\begin{array}{l}\text { Situation reporting system routinely used by planning staff to capture progress and report to national } \\
\text { authorities and WHO. }\end{array}$ \\
\hline & Accountability & Task tracking system routinely used for task management by operations staff; reports are generated for IM. \\
\hline & Operational support & Situational awareness products are kept current and posted within the EOC. \\
\hline & Administrative support & Centralized stock of office supplies available as needed. \\
\hline & Financial support & Expenditures are tracked and categorized to enable subsequent reimbursement. \\
\hline & Logistics support & Response teams are supplied as needed to sustain field operations. \\
\hline & Staffing support & Procedures exist for occupational safety and health screening of staff postresponse. \\
\hline & Communication support & Media management system is in place to service media inquiries responsively. \\
\hline \multirow[t]{5}{*}{ Infrastructure } & EOC facility & Breakout space is available for $\geq 1$ teams; all space is assigned or scheduled by EOC staff. \\
\hline & Power & Facility has operational power redundancy in place. \\
\hline & Communications infrastructure & $\begin{array}{l}\text { Communication infrastructure is routinely used to triage calls from, as well as communicate with, both } \\
\text { subnational levels and WHO (note: video teleconferencing capability is not included). }\end{array}$ \\
\hline & Information infrastructure & Operations staff have training on and can use all available IM infrastructure elements. \\
\hline & $\begin{array}{l}\text { Data processing and visualization } \\
\text { infrastructure }\end{array}$ & Data display screen(s) and associated processors used within the EOC to maintain situational awareness. \\
\hline
\end{tabular}

Abbreviations: Ebola = Ebola virus disease; EOC = emergency operations center; IM = incident manager; WHO = World Health Organization.

Dashboard tool-derived information was stored in a central data repository and shared with CDC Ebola response leadership and other programs within CDC. Deployed EMDT staff and headquarters staff used the information to coordinate activities at the national level in Guinea, Liberia, and Sierra Leone; address gaps in IMS capabilities; and inform decisions on resource allocation within each country. These data also provided information to agency leadership and higher levels.

EMDT reviewed situation reports and analyzed key programmatic accomplishments and milestones. To analyze dashboard data, ratings were converted from the six-point qualitative ordinal scale to quantitative scores ranging from 0 to 5 . For each country, a score was calculated for each domain equal to the median of its constituent element scores for each month during August 2014-June 2015. Data were analyzed using Microsoft Excel.

\section{Changes in Capacity for Emergency Management}

During August 2014-June 2015, basic emergency management capacity improved in all three countries. Weekly updates revealed improved capability in demonstrating IMS principles; key events and accomplishments are listed in Table 2. Dashboard scores generally reached and maintained their highest levels during October-December 2014 (Table 3), although additional gains and losses occurred after this period, some of which might be attributable to lower staffing levels over the December holiday season. Early in the response, some elements of capacity building were deemed high priority in all countries, such as appointing an incident manager, identifying and establishing an EOC facility, and ensuring response teams and logistic support were in place and used appropriately. Scores for other elements, such as administrative support and meeting management, did not improve as quickly; these were addressed later after more crucial elements were in place.

\section{Liberia}

EMDT began supporting the Liberian government's Ebola response on August 3, 2014. As of March 31,2016, a total of 17 EMDT members had provided 914 person-days of in-country technical support. When EMDT first became involved, Liberia's president already had appointed an incident manager, but the response was not following standard IMS principles, such as chain of command, incident action planning, and resource 
TABLE 2. Timeline of events in Ebola epidemic response — Liberia, Sierra Leone, and Guinea, August 2014-June 2015

\begin{tabular}{|c|c|c|}
\hline Date & Country & Activity \\
\hline \multicolumn{3}{|l|}{2014} \\
\hline August 3 & Liberia & Emergency Management Development Team begins work in country. \\
\hline August 10 & Sierra Leone & Emergency Management Development Team begins work in country. \\
\hline September 18 & Liberia & Use of interim EOC begins. \\
\hline September 22 & Guinea & Emergency Management Development Team begins work in country. \\
\hline October 7 & Sierra Leone & National Ebola response coordinator approves plans for PH NEOC. \\
\hline October 20 & Sierra Leone & United Kingdom takes over command of the response. \\
\hline October 23 & Guinea & Renovations of the national public health EOC start. \\
\hline October 27 & Sierra Leone & Response operations move to operate under the National Ebola Response Centre. \\
\hline November 1 & Guinea & All partner meetings begin to be held at the PH NEOC. \\
\hline November 12 & Liberia & Ground breaking on permanent PH NEOC. \\
\hline November 29 & Guinea & Inaugural reception for the National Ebola Response Call Center. \\
\hline December 13 & Sierra Leone & Ground breaking on permanent PH NEOC. \\
\hline \multicolumn{3}{|l|}{2015} \\
\hline February 5 & Liberia & $\begin{array}{l}\text { IMS workshop for } 30 \text { medical and public health students from the Young Liberian Professionals group (potential surge } \\
\text { staff for the response). }\end{array}$ \\
\hline February 10 & Liberia & First 3-day EOC operations and IMS workshop for 35 subnational and national EOC staff and county health officers. \\
\hline February 13 & Guinea & Incident manager approves Ebola staffing plan. \\
\hline February 18 & Liberia & Second 3-day EOC operations and IMS workshop for 31 subnational and national EOC staff and county health officers. \\
\hline March 17 & Sierra Leone & Half-day EOC management workshop for key MoHS staff on EOC management and organizational structure. \\
\hline March 18 & Sierra Leone & Signing and deed gifting ceremony for PH NEOC to the MoHS from CDC Foundation. \\
\hline March 20 & Guinea & Implements new strategy for response meeting coordination. \\
\hline April 27 & Guinea & PH NEOC establishes central e-mail address. \\
\hline May 10 & Liberia & Completion of preliminary construction of PH NEOC. \\
\hline June 1 & Guinea & Clearance and distribution protocols for recommendations from PH NEOC to subnational response staff are established. \\
\hline June 16 & Liberia & All response operations move into the PH NEOC. \\
\hline June 22 & Sierra Leone & All NERC and MoHS staff and partners begin operating out of the PH NEOC. \\
\hline
\end{tabular}

Abbreviations: Ebola = Ebola virus disease; EOC = Emergency Operations Center; IMS = Incident Management System; MoHS = Ministry of Health and Sanitation; PH NEOC $=$ Public Health National EOC.

TABLE 3. Domain scores* on a dashboard tool for measuring emergency management capacity, by month — Guinea, Liberia, and Sierra Leone, August 2014-June 2015

\begin{tabular}{|c|c|c|c|c|c|c|c|c|c|c|c|}
\hline \multirow[b]{2}{*}{ Country/Domain } & \multicolumn{11}{|c|}{ Domain scores } \\
\hline & $\begin{array}{c}\text { August } \\
2014\end{array}$ & $\begin{array}{c}\text { September } \\
2014\end{array}$ & $\begin{array}{c}\text { October } \\
2014\end{array}$ & $\begin{array}{c}\text { November } \\
2014\end{array}$ & $\begin{array}{c}\text { December } \\
2014\end{array}$ & $\begin{array}{c}\text { January } \\
2015\end{array}$ & $\begin{array}{c}\text { February } \\
2015\end{array}$ & $\begin{array}{c}\text { March } \\
2015\end{array}$ & $\begin{array}{l}\text { April } \\
2015\end{array}$ & $\begin{array}{l}\text { May } \\
2015\end{array}$ & $\begin{array}{l}\text { June } \\
2015\end{array}$ \\
\hline \multicolumn{12}{|l|}{ Guinea $^{\dagger}$} \\
\hline Staff & —§ & 1 & 2.5 & 4 & 4 & 4 & 4 & 3 & 3 & - & - \\
\hline Infrastructure & - & 1 & 1 & 3 & 3 & 3 & 3 & 4 & 4 & - & - \\
\hline Systems & - & 2 & 2 & 3 & 3 & 3 & 3 & 3 & 3 & - & - \\
\hline \multicolumn{12}{|l|}{ Liberia? } \\
\hline Staff & - & 2 & 3 & 3 & - & 3 & 3 & 3 & 3 & 3 & 3 \\
\hline Infrastructure & - & 1 & 3 & 3 & - & 2.5 & 2 & 2 & 2 & 3 & 3 \\
\hline Systems & - & 1 & 2 & 3 & - & 3 & 3 & 3 & 3 & 3 & 3 \\
\hline \multicolumn{12}{|l|}{ Sierra Leone } \\
\hline Staff & 2 & 2 & 3 & 4 & 4 & 4 & - & 4 & 4 & 4 & 4 \\
\hline Infrastructure & 1 & 1 & 2 & 3 & 3 & 3 & - & 3 & 3 & 3 & 3 \\
\hline Systems & 0 & 1 & 3 & 3 & 4 & 4 & - & 4 & 4 & 4 & 4 \\
\hline
\end{tabular}

* Domain scores are on a 0 to 5 ordinal scale, which reflect lowest to highest capacity.

† The dashboard tool was only used from September 2014 to the beginning of May 2015 because of implementation of other monitoring methods more suitable for Guinea's incident management system.

$\S$ No data were collected.

" The dashboard tool was not used until September 2014.

management. In addition, the response was being managed from space that was too small and lacked key technologic infrastructure. Early challenges included an insufficient number of trained logistic staff and a span of control too large for response leadership to manage effectively. Other challenges included difficulty mobilizing resources and insufficient coordination among response partner organizations. Initially, deployed EMDT staff supported Liberia's Ministry of Health in establishing an incident management structure and providing training on IMS principles (4). 
Liberia's Ministry of Health opened an interim EOC on September 18, 2014, with guidance and technical assistance from EMDT. During the first few months of the response, EMDT supported establishment of the national Ebola response call center, which was developed with sufficient technical infrastructure to be repurposed into a national dispatch center or EOC watch desk after the Ebola response. EMDT also supported the Ministry of Health in creating a task tracker for Liberian Ebola response leadership and a template to facilitate management during response updates. In addition, deployed EMDT staff conducted and coordinated four in-progress reviews (i.e., mid-response assessments) for Liberia's Ebola response leadership in November and December 2014.

In September 2014, deployed EMDT staff began to coordinate the building of a permanent national public health EOC facility with CDC partners in Liberia. The facility opened on June 16, 2015; it was used for all response meetings and has helped response staff coordinate activities and streamline communication among staff working in various technical areas.

Most work in Liberia focused on building capacity to coordinate emergency response by establishing subnational EOCs in the country's 15 counties. In February 2015, two 3-day emergency management training sessions were held for 48 subnational personnel, 10 national personnel, and eight county health officers focusing on IMS principles and approaches to coordinating national and subnational emergency management. To reinforce this training, EMDT supported Liberian Ebola response staff in developing and collecting situation reports to streamline communication between county and national EOCs. In May 2015, this staff and infrastructure, including subnational EOCs, supported a large measles vaccination campaign in country.

Emergency management capacity improved quickly in Liberia. Dashboard scores for the staff and infrastructure domains peaked (median: 3) by October 2014, with the systems domain following close behind (Table 3 ). Scores for staff and systems remained at these levels while the infrastructure score dropped in January 2015, recovering a few months later.

\section{Sierra Leone}

Since August 10, 2014, deployed EMDT staff and partners have supported efforts by the Sierra Leone Ministry of Health and Sanitation (MoHS) to build response capacity for public health emergency management in Sierra Leone. As of March 31, 2016, at total of 17 CDC staff (deployed through EMDT) provided 905 person-days of in-country technical support. These staff provided technical assistance to the Ebola response in Sierra Leone and focused on building emergency management capacity through engagements with the NERC, the MoHS, and other international partners, including WHO, Public Health England, and the United Kingdom Department for International Development.

Early in the response, deployed EMDT staff supported establishment of an IMS in Sierra Leone by providing technical assistance to strengthen the ministry's organizational response structure and recommending ways to expand response functions, such as setting up an Ebola response call center. Team members helped build system capacity by developing terms of reference for IMS staff (e.g., a document identifying mission, role-specific objectives, and responsibilities), an EOC operations guidebook, and standard operating procedures to streamline the submission of requests and proposals from field staff to the EOC. Throughout the response, deployed EMDT staff engaged the MoHS in building staff capacity by training ministry staff to enhance their knowledge of public health emergency management functions and EOC management and operations. These training sessions included three halfday workshops, six training sessions for district health medical teams, and one training session for MoHS national-level staff, reaching a total of 120 persons.

Originally, all response-related activities operated out of the WHO country office. In September 2014, as the response expanded with additional partners, deployed EMDT staff guided and coordinated establishment of an interim EOC at a Sierra Leone Armed Forces facility. In October 2014, the government of Sierra Leone established NERC, and a former Sierra Leone Minister of Defence assumed command of Ebola response activities. The Sierra Leone Office of National Security, Ministry of Defence, and the United Kingdom Department for International Development provided substantial assistance in support of the response. Deployed EMDT staff supported transition of the interim EOC to the United Nations Special Court compound in Freetown, which temporarily housed NERC, enabling closer coordination with international partners. NERC subsequently established 10 subnational level District Ebola Response Centres to support surge response to localized outbreaks. The national MoHS and subnational district health medical teams supported the response by providing technical scientific expertise to NERC and District Ebola Response Centres.

Throughout the response, deployed EMDT staff served as liaisons among CDC IMS leadership, NERC, and other MoHS officials while helping the MoHS develop its emergency management capacity. In addition to national-level response coordination, EMDT assisted NERC in completing assessments of IMS capabilities developed at a subnational level in the District Ebola Response Centres and helped the MoHS and other partners assess the long-term IMS and response capabilities of the district health medical teams. 
Although response operations continued under NERC, EMDT personnel acted as technical advisors to such partners as WHO and the CDC Foundation. The CDC Foundation funded a public health national EOC (PH NEOC) and on March 18, 2015, a deeding and gifting ceremony transferred ownership of the facility to the MoHS. In coordination with WHO, deployed EMDT staff helped the MoHS develop a strategy and a staffing model for the PH NEOC. In May 2015, CDC began assisting the NERC Transition Move Project, supported by the United Kingdom Joint Interagency Task Force, to develop plans to co-locate the Disease Prevention and Control Division of the MoHS and core Office of National Security functions with NERC in the PH NEOC. This colocation enabled the building of additional emergency management capacity for the MoHS by leveraging response skills from NERC for future operations; in June 2015, the MoHS and NERC officially began Ebola response operations from the PH NEOC. Full transition of emergency operations capability to the PH NEOC, led by the Office of National Security and the MoHS, occurred on January 1, 2016. Finally, deployed EMDT staff are now supporting the MoHS in developing a 1-year strategic plan to position MoHS to engage in long-term capacity building for public health emergency management.

Overall, the dashboard revealed marked gains across the three targeted domains of emergency management capacity building. The median score for the systems domain rose from 0 in August 2014 to 4 in December 2014 with a steep increase from September to October (Table 3). Scores for the staff and infrastructure domains also rose quickly. The median staff score began at 2 in August 2014 and increased to 4 in November 2014, and the infrastructure score rose from 1 to 3 during the same period. In addition, unlike the scores for Liberia and Guinea, scores for Sierra Leone either increased or remained steady; none ever declined.

\section{Guinea}

The first emergency management deployments to support Guinea's Ebola response began in country September 22, 2014. To help fulfill Guinea's need for French-speaking emergency managers, CDC partnered with PHAC, which led in-country technical assistance. When possible, PHAC staff were supported by additional deployed staff from CDC and the U.S. Department of Health and Human Services (HHS). As of March 31, 2016, the 29 persons deployed (9 from CDC, 2 from HHS, and 18 from PHAC) provided 1,374 person-days of in-country technical support in Guinea. These staff provided guidance and technical assistance to Cellule.

Through funding by the CDC Foundation, a call center was established and a government-owned building was renovated to function as the national EOC facility. Deployed staff assisted the call center through the development of standard operating procedures, scripts, and training sessions for call center staff and assisted Cellule by developing basic emergency management administration and other office systems for a streamlined and coordinated response. The systems created for the EOC of Cellule include a task tracker system used in national coordination meetings for increased accountability, standard operating procedures for $\mathrm{CDC}$ staff to submit mission orders to Cellule before traveling outside Conakry, a standard template for Cellule incident management meetings, and a functional e-mail box for Cellule staff and priority prefecture EOCs.

Deployed staff and partners supported capacity development for Guinea response staff by conducting ad hoc training of Cellule employees on foundational workplace skills, such as using e-mail, Microsoft PowerPoint, and Excel, and by embedding deployed staff and partners into critical response technical areas such as logistics. This support also created an environment in which the daily coordination of meetings and management of functional e-mail boxes is performed by Guinean staff.

Since March 2015, through a collaboration between PHAC, $\mathrm{CDC}$, the International Organization for Migration, and George Washington University, all of the five communal and 18 prefectural EOC structures put in place by the International Organization for Migration have been assessed, an emergency management curriculum and a train-the-trainer program developed, and principles of emergency management formally introduced to key leadership within Cellule. The national coordinator approved the proposed rollout of the emergency management program, which started in January 2016.

The dashboard tool highlighted gains in emergency management capacity in Guinea. The median score for the staff domain quickly increased from 1 in September 2014 to its maximum of 4 just 2 months later (Table 3). Likewise, the score for infrastructure increased from 1 in September 2014 to 4 in March 2015, but with two plateaus in the interim (from September 2014 to October 2014, when the median score was 1, and again from November 2014 to February 2015, when the median score was 3). Unlike the infrastructure score, which either rose or remained constant, the staff score declined from 4 in February 2015 to 3 in March 2015. The systems score began at 2 in September 2014 and increased to 3 in November 2014, where it remains.

\section{Conclusion}

CDC staff and partners deployed through EMDT provided emergency management technical assistance and guidance to 
the national Ebola responses in Guinea, Liberia, and Sierra Leone. This assistance included developing IMS goals and objectives, identifying gaps in response capabilities, and recommending strategies for coordinating response activities. EMDT staff, deployed personnel, and partners assisted all three countries in prioritizing foundational emergency management activities during the Ebola epidemic. As countries carried out activities, such as locating and equipping adequate work spaces, training response staff on IMS principles, and establishing basic plans and processes for public health emergency management, EMDT staff, deployed personnel, and partners provided support and technical expertise wherever needed.

The information provided in this report highlights the rapidity with which rudimentary emergency management capacities can be established with the application of focused technical assistance yet also reveals the challenge of progressing beyond basic staff, systems, and infrastructure. Integrating these capacities into a sustained and functional operation is difficult in any context, but all the more so in a resourcelimited setting containing a vulnerable public health and health care system and experiencing a widespread infectious disease outbreak. Likewise, balancing long-term capacity building with the need to execute actions quickly also proved challenging.

EMDT used the dashboard tool as one of multiple methods to capture progress in emergency management capacitybuilding efforts. The response context presented many challenges for effective assessment, and key limitations and areas for improvement emerged while using the dashboard and reviewing collected data. The response priorities and IMS functional groups varied from country to country and were at times not consistent with the domains listed in the dashboard. This variation was especially marked in Guinea, where formal IMS principles were not introduced until later in the response, and the day-to-day work was not always captured by the dashboard items. In addition, the constant turnover of deployed staff and the lack of standardized definitions within and across domains led to inconsistent interpretation of the indicators. Finally, although the tool was intended to help prioritize key IMS principles, the collected information was not always analyzed quickly enough to inform technical assistance. Now that this tool has been used for the first time in real-world conditions, it can be revised and improved.

A lesson learned is to not assume that the benefits of emergency management and IMS are easily observed at the outset of a crisis or emergency. During the early stages of this response, neither the principles of emergency management nor the benefits of implementing the system in country were well understood in the West African countries affected by Ebola. However, once the benefits of IMS were noticeable, country leadership requested additional assistance in emergency management; the requests for additional assistance also indicated that real-world use of IMS is the most effective way to demonstrate its value. As CDC continues to support the Global Health Security Agenda (5) in countries around the world, highlighting precisely how IMS enables a country to respond efficiently and effectively to a public health event or emergency is becoming increasingly important. In Liberia, Sierra Leone, and Guinea, the IMS structures for this response could become the foundational framework for a long-term public health emergency management program that has the staff, infrastructure, and systems in place to successfully prepare for and respond to public health events and emergencies.

\section{Acknowledgments}

EMDT, Atlanta-based: Bianca Alba, Angel Aviles, James Banaski, Jim Crockett, Yvette Diallo, Emily Dodd, Scott Naelitz, Andrea Neiman, John Yembu; deployed staff: Roodly Archer, Mark Austin, John Bermingham, Daniel Brencic, Valeria Carlson, Jim Crockett, Yvette Diallo, Shahul Ebrahim, Mark Hall, Mark Hansey, Bryan Heartsfield, Bill Howard, Harvey Howard, Thomas Jones, David Kennedy, Sharanya Krishnan, Jose Laguana, Travis Mann, David Maples, Eric Marble, Lise Martel, Chuck Menchion, James Mullikin, Twite wa Numbi Mulunda, Peter Paye, Michael Phipps, Luis Poblano, Nathan Pyles, Ed Rouse, Rajeev Sharma, Christopher Smith, Paul Smith, Dan Tuten; HHS: David Starr, Greg Grass; PHAC: Daniella Cole, Danielle Demers, Jean-François Duperré, Lise Gauthier, Christopher Hewson, Steven Kempton, Marc Lafontaine, Marc Lauzier, Jennifer McCrea-Logie, Lynn Menard, Claude Ouellette, Violaine Pilote, Lara Rooke, Lisa Sherman, Danny Sokolowski, Anne-Marie Ugnat, Tricia Vockeroth, David Zito; CDC Ebola response staff in Atlanta and in affected countries.

\section{References}

1. US Department of Homeland Security. National Incident Management System. Washington, DC: US Department of Homeland Security, Federal Emergency Management Agency; 2008. http://www.fema.gov/pdf/ emergency/nims/NIMS_core.pdf

2. Papagiotas SS, Frank M, Bruce S, Posid JM. From SARS to 2009 H1N1 influenza: the evolution of a public health incident management system at CDC. Public Health Rep 2012;127:267-74.

3. Leidel L, Groseclose S, Burney B, Navin P, Wooster M. CDC. CDC's Emergency Management Program activities-worldwide, 2003-2012. MMWR Morb Mortal Wkly Rep 2013;62:709-13.

4. Pillai SK, Nyenswah T, Rouse E, et al. Developing an incident management system to support Ebola response-Liberia, July-August 2014. MMWR Morb Mortal Wkly Rep 2014;63:930-3.

5. CDC. Global health security: vision and overarching target. Atlanta, GA: US Department of Health and Human Services, CDC. http://www.cdc. gov/globalhealth/security/pdf/ghs_overarching_target.pdf 